\title{
Empirical approach based on centrifuge testing for cyclic deformations of laterally loaded piles in sand
}

Truong, P.; Lehane, B. M.; Zania, Varvara; Klinkvort, Rasmus Tofte

Published in:

Geotechnique

Link to article, DOI:

10.1680/jgeot.17.p.203

Publication date:

2019

Document Version

Peer reviewed version

Link back to DTU Orbit

Citation (APA):

Truong, P., Lehane, B. M., Zania, V., \& Klinkvort, R. T. (2019). Empirical approach based on centrifuge testing for cyclic deformations of laterally loaded piles in sand. Geotechnique, 69(2), 133-145.

https://doi.org/10.1680/jgeot.17.p.203

\section{General rights}

Copyright and moral rights for the publications made accessible in the public portal are retained by the authors and/or other copyright owners and it is a condition of accessing publications that users recognise and abide by the legal requirements associated with these rights.

- Users may download and print one copy of any publication from the public portal for the purpose of private study or research.

- You may not further distribute the material or use it for any profit-making activity or commercial gain

- You may freely distribute the URL identifying the publication in the public portal 


\section{Accepted manuscript doi: 10.1680/jgeot.17.p.203}

\section{Accepted manuscript}

As a service to our authors and readers, we are putting peer-reviewed accepted manuscripts (AM) online, in the Ahead of Print section of each journal web page, shortly after acceptance.

\section{Disclaimer}

The AM is yet to be copyedited and formatted in journal house style but can still be read and referenced by quoting its unique reference number, the digital object identifier (DOI). Once the AM has been typeset, an 'uncorrected proof' PDF will replace the 'accepted manuscript' PDF. These formatted articles may still be corrected by the authors. During the Production process, errors may be discovered which could affect the content, and all legal disclaimers that apply to the journal relate to these versions also.

\section{Version of record}

The final edited article will be published in PDF and HTML and will contain all author corrections and is considered the version of record. Authors wishing to reference an article published Ahead of Print should quote its DOI. When an issue becomes available, queuing Ahead of Print articles will move to that issue's Table of Contents. When the article is published in a journal issue, the full reference should be cited in addition to the DOI. 


\section{Accepted manuscript doi: 10.1680/jgeot.17.p.203}

Submitted: 09 August 2017

Published online in 'accepted manuscript' format: 28 March 2018

Manuscript title: Empirical approach based on centrifuge testing for cyclic deformations of laterally loaded piles in sand

Authors: P. Truong*, B. M. Lehane*, V. Zania ${ }^{\dagger}$ and R. T. Klinkvort

Affiliations: *School of Civil, Environmental \& Mining Engineering, The University of Western Australia, 35 Stirling Highway, Crawley WA 6009, Australia; ${ }^{\dagger}$ Department of Civil Engineering, Technical University of Denmark, Nordvej, Building 119, 2800 Kgs. Lyngby;

Offshore geotechnics, Norwegian Geotechnical Institute, Sognsveien 72, N-0855 Oslo,

Norway

Corresponding author: B. M. Lehane, School of Civil, Environmental \& Mining Engineering, The University of Western Australia, 35 Stirling Highway, Crawley WA 6009, Australia. Tel.: +618 64882417 .

E-mail: Barry.Lehane@uwa.edu.au 


\section{Accepted manuscript doi: 10.1680/jgeot.17.p.203}

\section{ABSTRACT}

A systematic study into the response of monopiles to lateral cyclic loading in medium dense and dense sand was performed in beam and drum centrifuge tests. The centrifuge tests were carried out at different cyclic load and magnitude ratios, while the cyclic load sequence was also varied. The instrumentation on the piles provides fresh insights into the ongoing development of net stresses, bending moments and deflections as cycling progresses. Parallels between the test results and corresponding cyclic triaxial tests are drawn. The paper combines the results from this study with those from previous experimental investigations to provide empirical design recommendations for monopiles subjected to unidirectional cyclic loading.

KEYWORDS: Piles; Cyclic lateral load; Sand; Centrifuge testing. 


\section{Accepted manuscript doi: 10.1680/jgeot.17.p.203}

\section{BACKGROUND}

The preferred foundation type for offshore wind turbines is the monopile (or single pile), which has been used for $80 \%$ of currently installed offshore turbines (Pineda \& Tardieu, 2017). Existing methods for prediction of the lateral response of these piles, such as the API (2011) recommendations, are largely based on research on small diameter piles reported by Reese et al. (1974), Murchison \& O’Neill (1984), and others. Concern over the applicability of these recommendations to monopiles, which often have diameters in excess of $5 \mathrm{~m}$, has motivated a considerable body of research in the past decade. One of the important foundation considerations is the accommodation in design for lateral cycling of monopiles due to wind and wave loading over the life of the turbine. Such cycling can lead to the accumulation of a significant permanent rotation of a monopile and overlying tower, rendering the turbine un-serviceable. Wind turbine tilt tolerance and permanent foundation rotation at the soil surface is specified by the wind turbine manufacturer as it varies for different turbines. Golightly (2014) quotes a typical limiting rotation of $0.5^{\circ}$ inclusive of a $0.25^{\circ}$ construction tolerance suggested by DNV (2016), therefore giving an allowable accumulated rotation due to cycling of $0.25^{\circ}$.

This paper focuses on the response of monopiles in sand to (uni-directional) lateral cycling and draws on evidence reported in recent experimental research as well as observations made in new centrifuge-scale lateral pile cycling experiments to propose an empirical method for estimation of the accumulation of permanent rotations of monopiles in sand. Numerical research into the prediction of such rotations is still at the development stage (e.g. Achmus et al. (2009), Giannakos et al. (2012), Su \& Li (2013), Rudolph et al. (2014), Depina et al. (2015) \& Zachert et al. (2016)) and the experimental trends identified here can support the calibration of future numerical models.

To assist comparison with recent experimental research, the nature of the cyclic loads is defined using the cyclic load ratio $\left(\zeta_{c}\right)$ and cyclic magnitude ratio $\left(\zeta_{b}\right)$, defined as follows:

$$
\begin{aligned}
& \zeta_{c}=H_{\min } / H_{\text {max }}=M_{\min } / M_{\max } \\
& \zeta_{b}=H_{\text {max }} / H_{r e f}=M_{\max } / M_{\text {ref }}
\end{aligned}
$$

where $H_{\min }$ and $H_{\max }$ are the minimum and maximum horizontal loads applied to the pile with corresponding moments applied to the pile at the soil surface of $M_{\min }$ and $M_{\max }$; for two-way loading, $H_{\min }$ and $H_{\max }$ are negative and positive respectively. The reference horizontal force and applied moment $\left(H_{r e f}\right.$ and $\left.M_{r e f}\right)$ are those corresponding to monotonic loading at failure or at a reference displacement or rotation $\left(y_{\text {ref }}\right.$ or $\left.\theta_{\text {ref }}\right)$ at the soil surface. As a geotechnical failure for a laterally loaded pile in sand under monotonic loading can require large pile rotations, it has become common practice to define $H_{\text {ref }}$ at a smaller $\theta_{\text {ref }}$ value, such as the value of $4^{\circ}$ employed by Leblanc et al. (2010) and Klinkvort \& Hededal (2013).

A typical response to uniform lateral cycling is shown on Figure 1, which also defines the cyclic load and rotational stiffness $\left(K_{r}\right)$ parameters. Uniform cyclic loading causes a progressive accumulation of permanent pile rotation (and pile head displacement), with the additional rotation developed in each cycle reducing as the number of cycles $(N)$ increases. Although accumulated rotation is often considered to vary with the logarithm of the number of cycles (Long \& Vanneste, 1994), lateral pile experiments described by LeBlanc et al. (2010), Klinkvort \& Hededal (2013), Truong \& Lehane (2015) and Li et al. (2015), show that, for a given level and type of cycling, the ratio of rotation accumulated after $N$ cycles $\left(\theta_{N}\right)$ to the maximum (positive) rotation reached in the first cycle $\left(\theta_{1}\right)$ is best represented for rigid piles as a power function of $N$ i.e.

$$
\theta_{N}=\theta_{1} N^{\alpha_{r}}
$$




\section{Accepted manuscript doi: 10.1680/jgeot.17.p.203}

where $\alpha_{r}$ is referred to here as the accumulation coefficient (with respect to rotation). The equivalent equation written in terms of displacements $(y)$ at the ground surface is:

$$
y_{N}=y_{1} N^{\alpha_{y}}
$$

where $\alpha_{y}$ is the accumulation coefficient with respect to lateral pile displacement. Li et al. (2015), and others, show that $\alpha_{y}$ is a little larger than $\alpha_{r}$. This difference can be explained by an increase with cycling of the depth about which the pile rotates due, for example, to the formation of a 'post-hole' near the surface. The formation of post-hole is consistent with the slight increase in the maximum pile bending moment with $N$ observed by Verdure et al. (2003), and Rosquoet et al. (2007). Cuellar et al. (2011) used optical measurement techniques to deduce that lateral cycling causes an increase in sand density (and sand stiffness) with accompanying downward migration (or convection) of sand grains as the post-hole near the surface increases in size. The boundary conditions existing after $N$ cycles therefore differ from those after the first cycle of loading and this effect should be acknowledged when employing expressions such as equation (3), which relate the pile response after $N$ cycles to that at $N=1$.

Long \& Vanneste (1994) collated existing field test data from 34 studies and concluded, in general, that pile head movements were dependent on the nature of applied cyclic loads, the sand relative density $\left(D_{r}\right)$ and the pile installation method. The subsequent systematic experimental investigations of Rosquoet et al. (2007), Klinkvort \& Hededal (2013) and Truong \& Lehane (2015) show that the accumulation coefficient $\left(\alpha_{y}\right)$ depends primarily on the cyclic load ratio $\left(\zeta_{c}\right)$ and to a lesser extent the cyclic magnitude ratio $\left(\zeta_{b}\right)$, and varies from a negative value for two-way loading $\left(\zeta_{c}=-1\right)$ to between about 0.05 and 0.2 at $\zeta_{c}$ values in the range of -0.5 to 0.75 (noting $\zeta_{c}=0$ corresponds to one-way loading with $H_{\min }=0$ ). LeBlanc et al. (2010) and Albiker et al. (2017) present formulations based on 1-g small scale tests in which the accumulation coefficient is considered independent of sand relative density, although scale issues associated with the very low stress level prevalent in these tests need to be acknowledged. It is also of note that Albiker et al. (2017) observed a dependency of the accumulation coefficient on the lateral load eccentricity as well as a difference between rigid and flexible piles.

Cyclic loading applied to monopiles is not uniform and a number of studies have examined the ability of the method of superposition presented by Lin \& Liao (1999) to predict pile response under various packages of (uni-directional) cycles. Field tests in dense sand reported by Li et al. (2015) show that this method provided a reasonable predictive approach for cyclic histories involving one-way loading with progressively increasing cyclic magnitude ratios. However, Peralta \& Achmus (2010) showed in 1-g model experiments that the order in which a given set of cyclic packages was applied did influence the final values of accumulated rotations.

It is evident from the foregoing that a range of experimental observations have been made, largely in centrifuge scale model tests, but also in other 1-g small-scale laboratory tests and field scale tests. This paper extends this database of information using a carefully planned series of centrifuge tests and subsequently compiles all observations to develop recommendations for assessment of the accumulation of permanent rotations for monopiles installed in a range of sand densities. These data can be a useful validation tool for numerical modelling of the cyclic behaviour of laterally loaded piles in sand. The paper also investigates the potential of using cyclic triaxial tests to estimate the relevant value of the accumulation coefficient (equation 3). An empirical approach is then formulated based on the centrifuge test results, which can be used in design to estimate permanent rotations of piles in sand subjected to variable lateral cycling histories. The pile instrumentation employed 


\section{Accepted manuscript doi: 10.1680/jgeot.17.p.203}

facilitates examination of the development with cycling of the maximum and residual pile bending moments and quantification of the effects of cycling on post-cyclic monotonic pile response.

\section{CENTRIFUGE TESTS}

Lateral cyclic pile tests were performed in the drum centrifuge at the University of Western Australia (UWA) and in the beam centrifuge at the Technical University of Denmark (DTU). The preliminary series of tests performed in the drum centrifuge used a relatively small model pile and comprised application of only 50 cycles of lateral load. The series of beam centrifuge tests was more comprehensive and used a larger model pile with a greater number of cycles and load eccentricity; this test series involved a systematic investigation of the effects of cyclic load characteristics and cyclic load sequences, and also is the first test series to employ medium dense sand as well as dense sand in the centrifuge at in-situ stress levels. The test schedule along with the corresponding cyclic load characteristics for all the tests conducted are provided in Table 1 where the UWA monotonic test is prefixed with UWA-M, DTU monotonic tests are prefixed with DTU-M, UWA cyclic tests are prefixed with UWAC, and DTU cyclic tests are prefixed with DTU-C. Note that in this study, $H_{r e f}$ is defined at a rotation at the sand surface equal to $0.5^{\circ}$ to be consistent with serviceability requirements for wind turbine foundations. Measurements of pile head rotation were recorded with a resolution of about $0.02^{\circ}$. The flexural rigidities of the centrifuge piles are relatively high and such that, as shown later, rotated in a semi-rigid manner under application of loads (and hence in a similar way to full scale monopiles).

UWA drum centrifuge equipment and setup

The drum centrifuge tests were performed in 'UWA sand' (described below) at an acceleration of $250 \mathrm{~g}$. This centrifuge has an outer radius of $0.6 \mathrm{~m}$, channel depth of $0.175 \mathrm{~m}$ and width of $0.3 \mathrm{~m}$ (Stewart et al. 1998). A schematic of the test set-up is presented in Figure 2. The sand sample had a final depth in the channel of $170 \mathrm{~mm}$ and was prepared in flight using procedures similar to those described by Lehane \& White (2005). Core samples of the sand taken subsequent to testing and Cone Penetration Test (CPT) tests performed in flight confirmed a uniform relative density $\left(D_{r}\right)$ of $68 \pm 3 \%$ throughout the sample. The test pile, with details provided in Table 2, was an aluminium hollow cylindrical tube, fitted with 8 pairs of strain gauges in a half bridge and protected by a $0.5 \mathrm{~mm}$ thick layer of epoxy; these gauges were calibrated at $1-g$ in the laboratory and enabled measurement of bending strains and hence bending moments throughout the tests. The pile was initially installed at 1-g using a tool attached to the drum actuator. The installation tool was then exchanged for the lateral loading arm which had a wheel end to provide a single point of contact for load application. This arrangement allowed the pile head to rotate freely but could only apply one-way loading. After pile installation, the sample was slowly re-saturated while ramping up to $250 \mathrm{~g}$. Lateral loading commenced at least two hours after reaching $250 \mathrm{~g}$. The load controlled cycles were applied in a triangular waveform at a slow speed of $0.015 \mathrm{~mm} / \mathrm{s}$ to ensure fully drained conditions.

\section{DTU beam centrifuge equipment and setup}

The $2.5 \mathrm{~m}$ radius beam centrifuge tests at DTU was employed to carry out lateral pile tests in dry Fontainebleau sand (described below) at an acceleration of 60g. The strongbox had an internal diameter of $527 \mathrm{~mm}$ and internal height of $460 \mathrm{~mm}$. The sand samples were pluviated at 1-g into the strongbox using a tube that was manoeuvred manually in a circular motion at a constant drop height above the sand surface. Drop heights of $50 \mathrm{~mm}$ and $200 \mathrm{~mm}$ were 


\section{Accepted manuscript doi: 10.1680/jgeot.17.p.203}

employed to attain target $D_{r}$ values of $57 \%$ and $90 \%$ respectively. The sand was levelled off to give a final sample height $337 \mathrm{~mm}$. The densities of the samples were derived from core specimens and are reported in Table 1. CPT data confirmed the uniformity of the samples and indicated $D_{r}$ varied by less than 3\% from the target value throughout the depth of sample penetrated by the piles. Full details of the centrifuge and the sand preparation method are provided in Leth (2013).

The loading frame was secured on top of the strongbox, as shown in the schematic diagram in Figure 3. This frame allowed inflight pile installation and subsequent lateral loading without ramping down the centrifuge to switch pile head connections. Lateral loading was applied via the loading frame which was driven by a motor across the top of the sample. Load controlled cyclic loading was applied in a periodic trapezoidal form (see inset on Figure 8) with a period of 10s. A hinge at the top of the pile head allowed rotation during the application of lateral load. The pile head was, however, fixed in the vertical direction resulting in axial tensile forces when lateral loads were applied. These forces were measured and found to be minimal at the relatively small pile head rotations under consideration in this study; their effects are nonetheless likely to have had some influence during the post-cyclic tests when piles were subjected to rotations in excess of $5^{\circ}$. Numerical analyses reported by Karthigeyan et al. (2006) and Hazzar et al. (2017) indicated that the presence of axial pile forces has a minimal effect on the lateral sand response.

The (hollow steel) model pile employed had the dimensions and properties summarised in Table 2. The pile was fitted with 15 pairs of calibrated strain gauges arranged in a half bridge and protected by $1 \mathrm{~mm}$ thick layer of epoxy. Lateral movement of the pile was measured by two laser displacement transducers set at $20 \mathrm{~mm}$ and $70 \mathrm{~mm}$ above the sand surface.

\section{Strain gauge interpretation}

Both the UWA and DTU test series utilised instrumented piles to obtain full bending moment profiles during loading. The profiles of bending moments $(M)$ were used to interpret corresponding profiles of the net soil pressures $(P)$, pile rotation $(\theta)$ and lateral displacements $(y)$ using the standard beam equations (where $E I$ is the pile flexural rigidity) i.e.

$$
\begin{aligned}
& P \times D=-\frac{d^{2} M}{d z^{2}} \\
& y=\iint M / E I d z \\
& \theta=\frac{d y}{d z}
\end{aligned}
$$

Various curve fitting methods were trialled when deriving net pressures from bending moments. Overlapping cubic polynomials, proposed by Yang and Liang (2006), were found to be the most suitable and the interpreted $P-y$ responses gave the most accurate predictions of load-displacement curves observed in monotonic tests when re-input into a standard load transfer $(P-y)$ laterally loaded pile program. It should be noted that Fan \& Leong (2005), Zania \& Hededal (2011) and Suryasentana \& Lehane (2016) have used numerical analyses to show that $P-y$ curves derived from bending moment profiles are independent of the pile rigidity.

Two constants are required to determine lateral pile displacements $(y)$ using equation (5) and these are usually obtained using measurements of displacement at two different locations. Both sets of centrifuge tests had only one displacement reading near the pile head (as the top laser in the DTU test malfunctioned) and therefore, to obtain a second displacement value, it 


\section{Accepted manuscript doi: 10.1680/jgeot.17.p.203}

was assumed that zero pile deflection occurred at the (lowest) location where the net pressure was zero. This assumption was consistent with observations in the DTU tests when both laser displacement transducers were working.

\section{Sand sample properties}

The UWA and Fontainebleau silica sands have almost identical gradings, each having a mean effective particle size $\left(D_{50}\right)$ of $0.18 \mathrm{~mm}$ and a uniformity coefficient of about 1.6. Detailed descriptions of the properties of the UWA and Fontainebleau sands are provided in Bagbag et al. (2017) and Latini (2016) respectively.

Triaxial tests, with test details given in Table 3, were performed on medium dense $\left(D_{r}=\right.$ $55 \%)$ and dense $\left(D_{r}=90 \%\right)$ samples of Fontainebleau sand to assist interpretation of the lateral cyclic tests. Prior to shearing, the samples were consolidated isotropically to $100 \mathrm{kPa}$, which corresponds to the vertical effective stress at half the embedment of the piles in the DTU centrifuge. A single monotonic test and two one-way cyclic tests with maximum deviator stresses $\left(q_{\max }\right)$ of 0.5 and 0.75 times the ultimate deviator stress $\left(q_{f}\right)$ were carried out for each sand density. For the medium dense sand sample subjected to cycling at $0.5 q_{f}$, two additional packages of one-way cycles with maxima of $0.75 q_{f}$ and $0.2 q_{f}$ were applied to compare the response to different cyclic load packages with a similar loading regime in the centrifuge. The responses observed in all of the triaxial tests are compared below with the lateral pile test results.

\section{PILE TEST OBSERVATIONS}

\section{Monotonic tests}

The variations of the normalised applied lateral load $(H)$ with rotation $(\theta)$ and normalised displacement $(y / D)$ at the ground surface for the monotonic tests are plotted on Figure 4; test details are provided in Table 1. The normalisation adopted for lateral load is the same as that employed by LeBlanc et al. (2010), where $\sigma_{v L}^{\prime}$ is the in-situ vertical effective stress at the base of the pile. This normalisation allows comparison of Test UWA-M, which was conducted in saturated conditions, with Tests DTU-M-1 and DTU-M-2 which were performed in dry sand.

It is evident that capacity at large rotations and displacements will increase with the sand relative density $\left(D_{r}\right)$ and the pile slenderness ratio $(L / D)$. However the normalised reference lateral loads $\left(H_{r e f}\right)$, defined in this study at a small deformation of $0.5^{\circ}$ rotation, show a small dependence on $D_{r}$ for a fixed $L / D$. Normalised $H_{r e f}$ values are $0.15,0.47$ and 0.54 in tests UWA-M, DTU-M-1 and DTU-M-2 respectively. The trends found in centrifuge tests of Klinkvort et al. (2013) and Dyson \& Randolph (2001) suggest that the softer variation of $H /\left(\sigma_{v L}^{\prime} D L\right)$ with $y / D$ seen in test UWA-M is, at least in part, due to its 1 -g installation. The difference between the two pile rigidity indices (EI), given in Table 2, also contributes to the softer overall pile behaviour in UWA-M. The ratio of cycling induced displacements to the monotonic displacement for the UWA piles, discussed below, is likely to be less influenced by their installation at $1-g$.

\section{Accumulation of permanent rotation}

The accumulation of permanent rotations with cycling in one-way cyclic tests $\left(\zeta_{c} \geq 0\right)$ is investigated on Figure 5a, which uses logarithmic axes to present the variation with the number of cycles $(N)$ of the measured maximum rotations after $N$ cycles $\left(\theta_{N}\right)$. The near linear variations seen for each designated test are indicative of constant accumulation coefficients $\left(\alpha_{r}\right)$ and confirm the general suitability of equation (3a). It is evident on inspection of Figure $5 \mathrm{a}$ that the slopes of these variations tend to reduce with increasing density. While these slopes are not affected significantly by the cyclic magnitude ratio $\left(\zeta_{b}\right), \theta_{N}$ clearly increases 


\section{Accepted manuscript doi: 10.1680/jgeot.17.p.203}

with the level of cycling (i.e. with $\zeta_{b}$ ). This tendency is incorporated in equation (3a) by allowing $\theta_{N}$ to vary directly with $\theta_{1}$. Evidence in support of this approach is apparent on Figure $5 \mathrm{~b}$ which shows very similar variations for respective relative densities of $\theta_{N} / \theta_{1}$ ratios with $N$ (using logarithmic axes) for tests with a range of $\zeta_{b}$ values but similar $\zeta_{c}$ values (of close to zero).

Under 2-way cycling $\left(\zeta_{c}<0\right)$, the test with $\zeta_{c}=-0.53$ and $\zeta_{b}=0.47$ (DTU-C-5) showed a continual increase in the accumulated rotation in the direction of the load cycle bias, with $\alpha$ similar to that of one-way cycling at the same density. However for test DTU-C-6, with near symmetrical two-way loading $\left(\zeta_{c}=-1.13\right.$ and $\left.\zeta_{b}=0.45\right)$, the accumulated rotation is very small and the pile moves slightly 'backwards' from the initial forward movement direction (largely due to the negative bias of $\zeta_{c}$ ).

Changes in pile lateral stiffness with cycling

A large change in rotational stiffness of a monopile over its lifetime could be an important consideration for assessment of the dynamic response of offshore wind turbines. The unloadreload rotational stiffness, $K_{r, N}$ (as defined in Figure 1) increased with the number of cycles in all experiments. However, the increases after about 10 cycles were very small (i.e. $K_{r, 10} \sim$ $\left.K_{r, 500}\right)$ and $K_{r}$ stabilised at value referred to here at $K_{r, s t a b}$. The ratio of this stabilised value to the $K_{r}$ value observed at $N=1\left(K_{r l}\right)$ is plotted on Figure 6 against the cyclic magnitude ratio $\left(\zeta_{b}\right)$ for the test piles installed in medium dense and dense Fontainebleau sand.

It is evident from Figure 6 that sand density and cyclic load ratio $\left(\zeta_{c}\right)$ have little influence on the relative change in rotational stiffness and the dominant factor affecting this change is the cyclic magnitude ratio $\left(\zeta_{\mathrm{b}}\right)$. However, even for this ratio, when cyclic load levels are within expected design levels (i.e. $\zeta_{\mathrm{b}}<0.75$ ), the maximum observed relative increase in stiffness is only 1.6. Similar observations were made by Verdure et al. (2003), Rosquoet et al. (2007) and Klinkvort \& Hededal (2013). Zania (2014) shows that a $60 \%$ increase in head stiffness for a typical offshore monopile can lead to a 5 to $10 \%$ increase in the wind turbine eigenfrequency. For a wind turbine designed based on the soft-stiff approach, this increases the potential for resonance of the turbine with the blade passing frequency.

Pile bending moments

Bending moments at peak lateral load $\left(M_{\max }\right)$ at $N=1,100$ and 500 are shown on Figure $7 \mathrm{a}$ and $7 \mathrm{~b}$ for two one-way tests in medium dense sand (DTU-C-1 and DTU-C-2). It is seen that, for DTU-C-1 with a typical design $\zeta_{b}$ value of 0.49 , the maximum pile bending moment increased by about $30 \%$ after 500 cycles and the location of this maximum increased from a normalised depth $(z / D)$ of 2 to 2.75. Maximum moments in the denser sand samples with the same $\zeta_{b}$ value (Test DTU-C-7) presented in Figure $7 \mathrm{~d}$ increased by only about $10 \%$ over the same number of cycles. These trends are consistent with the observed formation of a posthole at the ground surface during cycling, with a larger post-hole forming in the less dense sand. Interestingly, for very high level cycling $\left(\zeta_{b}=1.0\right)$ in both medium dense and dense sand, there is little increase in bending moment (e.g. see profiles for DTU-C-2 on Figure 7b). As seen on Figure 7c, changes in maximum moment are also minimal for two-way cycling in test DTU-C-6, although the moment increases on the reverse loading side due to the negative cycling bias $\left(\zeta_{c}=-1.13\right)$, with the point of maximum moment moving upwards from $\mathrm{z} / \mathrm{D} 2.5$ to $\mathrm{z} / \mathrm{D} \sim 1.5$.

The minimum bending moments $\left(M_{\min }\right)$ plotted on Figure $7 \mathrm{a}, 7 \mathrm{~b}$ and $7 \mathrm{~d}$ correspond to residual bending moments for the one-way tests, DTU-C-1, DTU-C-2 and DTU-C-7. These 'locked-in' moments are comparable but, in test DTU- C-1 and DTU-C-7, correspond to almost $50 \%$ of $M_{\max }$ at $z / D=3.5$ after application of 500 cycles. The existence of such 


\section{Accepted manuscript doi: 10.1680/jgeot.17.p.203}

significant 'locked-in' or residual moments, while also having been observed by Kirkwood \& Haigh (2014), is often not recognised in typical $p$ - $y$ analyses and reflects the changes due to cycling of the density and stress regime as well as the sand surface profile. As for the Kirkwood \& Haigh (2014) study, the experiments indicated greater locked-in moments and lateral stresses at larger $\zeta_{c}$ values; such lateral stresses can be beneficial in reducing fatigue damage because of the associated reduced amplitude of lateral stress variations.

\section{Pile deflections}

The pile deflections derived from integration of the bending moment profiles (equation 5) are plotted on Figure 7 at the peaks and troughs of the applied lateral cycling. The profiles are indicative of a rigid pile response with rotation occurring at a normalised depth $(z / D)$ of 4.5 to 5 diameters, which is approximately $80 \%$ of the overall pile length. The UWA piles had a longer $L / D$ ratio of 11.4 and also displayed a semi-rigid response with rotation occurring at $z / D \sim 7$. The lateral displacements in the two-way cyclic test (DTU-C-6) after 300 cycles are the same as, or smaller than, those experienced at the peak of the first cycle.

Net pressures on piles

Net pressures derived by differentiation of the moment profiles (equation 4) for tests DTU-C1, DTU-C-2, DTU-C-6, DTU-C-7 and UWA-C-4 are also provided on Figure 7. The pressure distribution for the DTU piles in medium dense sand shows more clearly than the pile deflection that the depth of the point of rotation increases from a normalised depth of 4.5 at $N=1$ to 4.7 at $N=500$ (noting that the rotation point is the deepest level at which the net pressure is zero). With an increasing number of cycles, the calculated net pressures at shallow depths in test DTU-C-1 reduce while those at deeper levels increase; these trends are in line with the formation of the depression (or post-hole) at the rear side of the pile. Net pressures derived in Test DTU-C-2 at maximum lateral load and at the peaks and troughs of the cycles showed little change with cycling, as reflected by the stable profile of maximum moment evident on Figure $7 \mathrm{~b}$. There is an increase in the magnitude of the maximum absolute net pressures in DTU-C-6 (due presumably to densification) and this leads to an upward movement of the level of pile rotation (where net pressures are zero) and a reduction in the depth to the location of maximum net pressure.

\section{Effect of pile aspect ratio}

The effect of the pile aspect ratio (L/D) can be observed in Figures 7a and 7e which plot the profiles of net pressure, moment and displacement for one-way loading of piles with $\mathrm{L} / \mathrm{D}=6$ and 11.4. It is evident that the depth at which the maximum bending moment occurs is generally similar for both cases (2.5 to 3D), while the level of rotation for the longer and shorter piles remains fixed at normalized depths of $\mathrm{z} / \mathrm{D} \sim 7$ and $\mathrm{z} / \mathrm{D} \sim 4.7$ respectively. As cycling progresses, greater residual net lateral pressures and moments are recorded at depth when the longer pile is unloaded, in line with the tendency for greater residual lateral displacements. The general deflected shapes of both the shorter and longer piles have a typical semi-rigid profile at the beginning and completion of the cycling imposed.

Effects of cyclic load sequence

Monopiles can be subjected to a wide range of cyclic loading events. To investigate the dependence of accumulated pile head rotations on cyclic history for uni-directional loading, the centrifuge experiments involved application of three packages of cycles applied in different sequences. The measured pile head rotations $\left(\theta_{N}\right)$ in medium dense dry Fontainebleau sand for one-way cycling $\left(\zeta_{c} \sim 0\right)$ for three 500 cycle packages with different cyclic magnitude ratios $\left(\zeta_{b} \sim 0.5,0.75\right.$ and 1.0) are plotted on Figure 8a for three sequences. The final accumulated rotations after the total of 1500 one-way cycles are $1.25^{\circ}, 1.65^{\circ}$ and 


\section{Accepted manuscript doi: 10.1680/jgeot.17.p.203}

$1.9^{\circ}$ and the difference between these rotations reflects the degree of dependence on the order of the load cycling. It is also evident that application of higher levels of cycling after initial lower level cycling leads to greater rotations than if high level cycling precedes lower level cycling.

Figure $8 \mathrm{~b}$ presents a similar set of measurements for another set of cyclic packages each with 300 cycles and the same $\zeta_{b}$ value of approximately 0.5 but with different $\zeta_{c}$ values. The dependence on the sequence of the cyclic packages is more evident for these cases. It is seen, in test DTU-C-4 for example, that there is a dramatic reduction in rotation in the final of the three packages when the value of $\zeta_{c}$ becomes progressively more negative (i.e. the loading moves from one-way to two-way). This is a sharp contrast to the response seen in Test DTUC-5 which had a positive $\zeta_{c}$ in the last package and ended up having three times the rotation that was measured in test DTU-C-4.

Post-cyclic response

The variation of the normalised lateral load with pile head rotation measured during postcyclic monotonic pushes performed in the centrifuge tests are compared on Figure 9 with the responses measured in monotonic tests. The plotted responses for the post-cyclic tests start from the permanent rotation induced by their cyclic histories summarised in Table 1.

Although the vertical restraint at the top of the DTU piles may have had a small effect on the magnitude of the capacities recorded (as discussed previously), both the UWA and DTU tests indicate that the post-cycling capacity of piles which did not suffer a significant permanent rotation during cycling (i.e. typically less than $0.25^{\circ}$ ) is the same or greater than the monotonic capacity. Post-cycling capacities measured after piles experienced a rotation of $0.5^{\circ}$ tend to be lower than the monotonic capacities, although this finding is not of major consequence for wind turbine monopiles, which need to restrict total rotations to less than $0.5^{\circ}$.

\section{DISCUSSION}

Accumulation of displacement with uniform cycling

It has been seen that equation (3) provides a reasonable representation of the accumulated rotations measured in the DTU and UWA centrifuge tests. The accumulation coefficient in these tests was not sensitive to the cyclic magnitude ratio $\left(\zeta_{b}\right)$ but varied with the sand density and the cyclic load ratio $\left(\zeta_{c}\right)$. These test results are now compared with measurements reported in field tests by Li et al. (2015) and in similar centrifuge experiments reported by Klinkvort \& Hededal (2013) and Rosquoet et al. (2007). Measured trends are examined using the $\alpha_{y}$ coefficient (equation $3 b$ ) as the latter two of these investigations did not report pile head rotations. For the tests in this study, the value of $\alpha_{r}$ was typically equal to $\left(\alpha_{y}-0.04\right)$. It should also be noted that the study of Rosquoet et al. (2007) indicated pile displacement profiles that were characteristic of a flexible pile response, rather than the rigid pile rotation mechanism observed in the remaining experiments. Relevant details for all experiments are provided in Table 2.

Close examination of the results of all tests indicated that $\alpha_{y}$ was largely independent of $\zeta_{b}$. Values of $\alpha_{y}$ recorded in pure one-way cyclic tests (with $\zeta_{c} \sim 0$ ) are plotted against the initial sand relative density $\left(D_{r}\right)$ on Figure 10a. $\alpha_{y}$ clearly reduces with increasing $D_{r}$ and also tends to be a little larger at low pile slenderness ratios $(L / D)$. No systematic relationship between $\alpha_{y}$ and the eccentricity of applied load $(e / D)$ was apparent. The following equation, which is plotted on Figure 10, yields a near upperbound value for $\alpha_{y}$ :

$$
\alpha_{y}=0.3-0.22 D_{r} \quad \text { for } \zeta_{c}=0, D_{r}>0.5, L / D<7
$$




\section{Accepted manuscript doi: 10.1680/jgeot.17.p.203}

All $\alpha_{y}$ values are plotted against $\zeta_{c}$ on Figure $10 \mathrm{~b}$, which uses equation 8 to normalise $\alpha_{y}$ values for effects of relative density. An upperbound curve to the dataset is shown on Figure $10 \mathrm{~b}$ and leads to the following proposal for design of typical monopiles (for which $L / D<7$ ):

$$
\alpha_{y}=\left(0.3-0.22 D_{r}\right)\left[1.2\left(1-\zeta_{c}^{2}\right)\left(1-0.3 \zeta_{c}\right)\right] \quad D_{r}>0.5
$$

Figure 10b shows that there is a progressive accumulation of permanent displacement when the cyclic load ratio $\zeta_{c}$ exceeds about -0.5 . However, negative $\alpha_{y}$ values, and hence a reduction in accumulated displacements, are more typical when $\zeta_{c}$ is less than -0.5 .

Assessment of the accumulation coefficient, $\alpha$

Equation (9) was derived for tests in fine, uniform silica sands, such as UWA, Fontainebleau and Blessington sands, and is applicable for assessment of cycling induced displacement for monopiles in these kinds of sands. It is of interest to examine if standard cyclic triaxial testing can be used to provide guidance to designers on the likely value of $\alpha$ in other sand types.

To examine this potential, monotonic and one-way cyclic triaxial tests were performed on Fontainebleau sand, as described above and with details summarised in Table 3. The measured variations of axial strain $\left(\varepsilon_{a}\right)$ with the number of (one way) cycles $(N)$ are plotted on Figure 11 using logarithmic axes. It is evident that $\varepsilon_{a}$ varies with $N$ in an analogous way to the variations of $\theta$ with $N$ presented on Figure 5. The slopes of these trend lines (on logarithmic axes), referred to as $\alpha_{\text {triax }}$, average at 0.14 for the medium dense sand with a single value of 0.09 measured in the dense sand and are plotted for comparative purposes on Figure 10a. While factors such as the mode of cycling and the sample stress level may lead to modest changes in $\alpha_{\text {triax }}$, it is evident that, as for $\alpha_{\mathrm{r}}$ and $\alpha_{y}, \alpha_{\text {triax }}$ reduces with an increase in sample density and is virtually independent of the cyclic magnitude level $\left(q_{\max } / q_{f}\right)$.

The value of $\alpha$ cannot be expected to be the same as $\alpha_{\text {triax }}$, simply because cyclic loading of piles is a boundary value problem with changing boundaries, whereas a triaxial test measures the response of an element. Nevertheless, the similarity of their controlling factors and their relatively close agreement in terms of magnitude (see Figure 10a) indicate that triaxial cyclic testing can provide insights for designers into expected lateral cyclic response in sands for which no previous experience exists.

\section{Effects of loading sequence}

As shown on Figure 8, the DTU centrifuge experiments incorporated application of a series of uni-directional cyclic load packages (each with a set number of cycles and given $\zeta_{b}$ and $\zeta_{c}$ ratios). It was seen that the loading sequence did affect the magnitude of the final value of rotation accumulated although the effect was more significant when both one-way and twoway cyclic wave packages were applied. Simple ways to assess the likely amount of the maximum permanent rotation are presented in the following.

For the tests involving one-way load packages, best predictions are obtained using the superposition approach, described by Lin \& Liao (1999). In application of this method, the accumulation coefficient is found from equation (9) and $\theta_{1}$ can be obtained from a site specific monotonic test or from predictive methods such as Suryasentana \& Lehane (2016) or API (2011). Predictions for the rotations at the peak of the cycles for specific cyclic packages applied (see Table 1) in four DTU tests are compared with the observations on Figure 12a to $12 \mathrm{~d}$. The value of $\alpha_{r}$ employed for these calculations was taken to be 0.04 less than $\alpha_{y}$ (calculated using equation 9), in line with observations in these tests. Reasonable agreement is apparent although it is evident that the final predicted rotation can be in error by up to $30 \%$. As expected, the approach leads to insignificant increases in rotation when the cyclic magnitude ratio $\left(\zeta_{b}\right)$ is lower than in a preceding load package.

It has been seen that significant permanent rotations do not occur under two-way loading when the cyclic load ratio $\left(\zeta_{c}\right)$ is less than about -0.5 . There is not a simple superposition 


\section{Accepted manuscript doi: 10.1680/jgeot.17.p.203}

approach that can be used to predict the trends with cyclic histories involving negative $\zeta_{c}$ values. However, given that the main interest of the designer is the assessment of the maximum rotation under a given set of cyclic packages, it is proposed that predictions are obtained for the packages arranged in order of increasing accumulation coefficient (e.g. as obtained from equation 9), and then applying the superposition method and assuming no rotation accumulation when $\zeta_{c}$ is less than -0.5. This approach is compared on Figures 12e$12 \mathrm{~h}$ and seen to provide an upper bound to the rotation that can be expected for these cyclic packages.

It is of interest to note that a number of different one-way cyclic packages were applied in the triaxial tests on Fontainebleau sand, referred to above. The test results showed excellent agreement with the superposition approach, which suggests that the discrepancies observed in Figure $12 \mathrm{a}$ to $12 \mathrm{c}$ (which plot results for the same cyclic packages applied in different sequences) reflect the changes developing adjacent to a cyclically load pile in sand; these changes include ongoing modifications to the size and geometry of a post-hole, alterations to the in-situ sand densities and increases in residual net stresses (which alter the applied cyclic load ratios at any given level in the soil).

\section{CONCLUSIONS}

This paper has presented results from a new series of centrifuge tests involving lateral cycling of instrumented piles in sand. These have added fresh insights into the factors controlling the accumulation of cyclic displacements and shown that:

(i) The rotation generated by lateral cycling of piles is proportional to the rotation experienced under monotonic loading at the same peak cyclic load and varies with the number of cycles raised to a power, referred to as the accumulation coefficient $(\alpha)$.

(ii) The accumulation coefficient $(\alpha)$ depends primarily on the cyclic load ratio $\left(\zeta_{c}\right)$ and the sand relative density. Highest permanent rotations are developed by short piles in looser sands subjected to one-way loading or biased one-way loading $\left(\zeta_{c}>-0.5\right)$.

(iii) The accumulation coefficient measured in one-way cyclic triaxial tests is less than that observed in cyclic lateral pile tests, but shows a similar dependence on relative density and cyclic load ratio.

(iv) Residual (locked-in) net lateral stresses develop during cycling and can reach values that are up to $50 \%$ of the maximum moments induced by the peak lateral load. The existence of these stresses are a reflection of the changes in boundary conditions around laterally cycled piles, which include the development of post-holes and changing sand densities. The locked-in moments are more prominent at lower relative densities, for one way loading and at higher cyclic magnitude ratios.

(v) Post-cyclic capacity of monopiles is similar to the monotonic capacity if the permanent rotation experienced during cycling is less than the typical serviceability limit of $0.5^{\circ}$.

A combination of these centrifuge results with data from other similar investigations in sand has enabled the development of general guidelines. An empirical framework is presented which can be used as a design tool in the assessment of permanent pile displacements and rotations for laterally cycled piles in sand.

\section{ACKNOWLEDGEMENTS}

The authors are indebted to the contributions of the centrifuge operators Mr John Troelsen at DTU and Mr Manuel Palacios at UWA, as well as assistance from academic colleagues Dr Wen-Gang Qi and Mr Mads Frederiksen. The funding provided by the Australian Research Council is also gratefully acknowledged. 


\section{Accepted manuscript doi: 10.1680/jgeot.17.p.203}

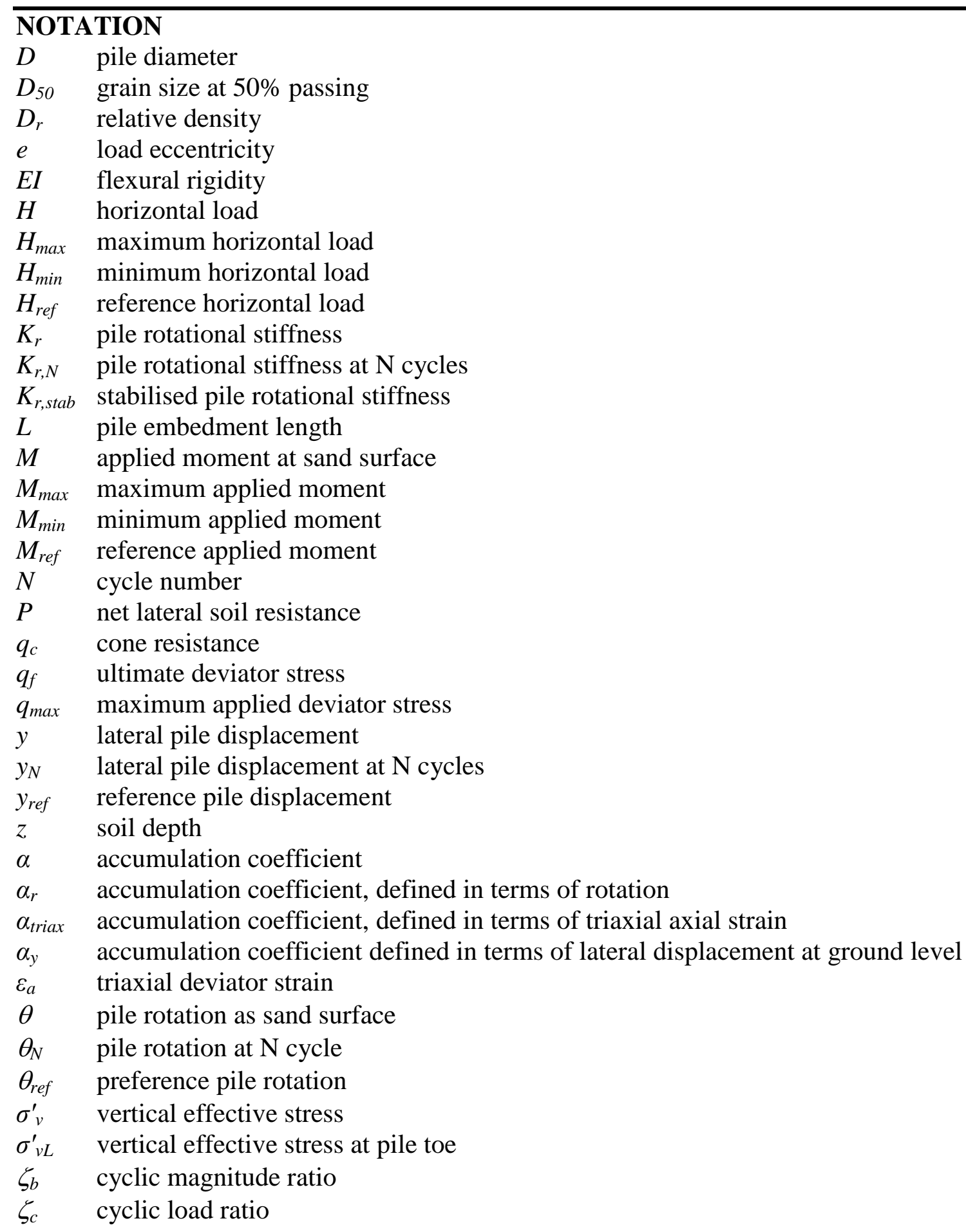




\section{Accepted manuscript doi: 10.1680/jgeot.17.p.203}

\section{REFERENCES}

Achmus, M., Kuo, Y.S. \& Abdel-Rahman, K. (2009). Behavior of monopile foundations under cyclic lateral load. Computers and Geotechnics 36, No. 5, 725-735.

Albiker, J., Achmus, M., Frick, D. \& Flindt, F. (2017). 1 g Model Tests on the Displacement Accumulation of Large-Diameter Piles Under Cyclic Lateral Loading. Geotechnical Testing Journal 40, No. 2, 20160102.

American Petroleum Institute (2011) Geotechnical and Foundation Design Considerations, API Recommended Practice 2GEO, 1st edn, Washington.

Bagbag A., Lehane B.M. and Doherty J.P. (2016). Predictions of footing and pressuremeter response in sand using a hardening soil model. ICE Geotechnical Engineering 170, No.6, 479-492.

Cuéllar, P., Georgi, S. \& Baebler, M. (2012). On the quasi-static granular convective flow and sand densification around pile foundations under cyclic lateral loading. Granular Matter 14, 11-25.

Depina, I., Le, T.M.H, Eiksund, G. \& Benz, T. (2015). Behavior of cyclically loaded monopile foundations for offshore wind turbines in heterogeneous sands. Computers and Geotechnics 65, 266-277.

Det Norske Veritas GL (2016). Support structures for wind turbines, DNVGL-ST-0126, April 2016 edn.

Dyson, G. \& Randolph, M. (2001). Monotonic lateral loading of piles in calcareous sand. Journal of Geotechnical and Geoenvironmental Engineering 127, No. 4, 346-352.

Fan, C.C. \& Long, J.H. (2005). Assessment of existing methods for predicting soil response of laterally loaded piles in sand. Computers and Geotechnics 32, 274-289.

Giannakos, S., Gerolymos, N. \& Gazetas, G. (2012). Cyclic lateral response of piles in dry sand: Finite element modeling and validation. Computers and Geotechnics 44, 116-131.

Golightly, C. (2014). Tilting of monopiles: Long, heavy and stiff; pushed beyond their limits. Ground Engineering, January, 20-23.

Hazzar, L. Hussien, M.N., \& Karray, M. (2017). Influence of vertical loads of lateral response of pile foundations in sands and clays. Journal of Rock Mechanics and Geotechnical Engineering 9, 291-304.

Karthigeyan, S., Ramakrishna, V.V.G.S.T. \& Rajagopal, K. (2006). Influence of vertical load on the lateral response of piles in sand. Computers and Geotechnics 33, No. 2, 121-131.

Kirkwood, P. \& Haigh, S.K. (2014). Centrifuge testing of monopiles subject to cyclic lateral loading. Proc. International Conf. Physical Modelling in Geotechnics, Perth 2, 827-831.

Klinkvort, R. T. \& Hededal, O. (2013). Lateral response of monopile supporting an offshore wind turbine. Geotechnical Engineering 166, No. GE2, 147-158.

Klinkvort, R. T., Hededal, O. \& Springman, S. (2013). Scaling issues in centrifuge modelling of monopiles. International Journal of Physical Modelling in Geotechnics 13, No. 2, 38-49.

Latini, C. (2017). Triaxial Tests in Fontainebleau Sand. Technical University of Denmark Internal Report, Copenhagen, 7 April 2017.

Leblanc, C., Houlsby,G.T. \& Byrne, B. (2010). Response of stiff piles in sand to long-term cyclic lateral loading. Géotechnique 60, No. 2, 79-90.

Lehane, B.M. \& White, D.J. (2005). Lateral stress changes and shaft friction for model displacement piles in sand. Canadian Geotechnical Journal 42, No. 4, 1039-1052.

Leth, C.T. (2013). Improved Design Basis for Laterally Loaded Large Diameter Pile: Experimental Based Approach. PhD Thesis - Aalborg University, Aalborg.

Li, W., Igoe, D. \& Gavin, K. (2015). Field tests to investigate the cyclic response of monopiles in sand. Geotechnical Engineering 168, No.5, 407-421. 


\section{Accepted manuscript doi: 10.1680/jgeot.17.p.203}

Lin, S.S. \& Liao, J.C. (1999). Permanent Strains of Piles in Sand due to Cyclic Lateral Loads. Journal of Geotechnical and Geoenvironmental Engineering 125, No. 9. 798-802.

Long, J.H. \& Vanneste, G. (1994). Effects of cyclic lateral loads on piles in sand. Journal of Geotechnical Engineering 120, 225-244.

$\mathrm{Mu}$, L.L., Huang, M.S., Zhang, J \& Feng, C.M. (2015). Influence of vertical loads on the behavior of laterally loaded large diameter pile in sand. Frontiers in Offshore Geotechnics III, Oslo, 729-734.

Murchison, J. \& O’Neill, M. (1984). Evaluation of p-y relationships in cohesionless soils. Proc. Analysis and Design of Pile Foundations. San Francisco, 174-191.

Peralta, P. \& Achmus, M. (2010). An experimental investigation of piles in sand subjected to lateral cyclic loads. Proc. International Conf. Physical Modelling in Geotechnics, Zurich, 985-990.

Pineda, I. \& Tardieu, P. (2017). The European offshore wind industry - Key trends and statistics 2016. Wind Europe. January.

Reese, L.C., Cox, W.R. \& Koop, F.D. (1974). Analysis of laterally loaded piles in sand. Proc. Offshore Technology Conf., Houston, 473-483.

Rosquoët, F., Thorel, L.. Garnier, J. \& Canepa Y. (2007). Lateral cyclic loading of sandinstalled piles. Soils and foundations 47, No. 5, 821-832.

Rudolph, C., Bienen, B. \& Grabe, J. (2014). Effect of variation of the loading direction on the displacement accumulation of large-diameter piles under cyclic lateral loading in sand. Canadian Geotechnical Journal 51, No. 10, 1196-1206.

Schneider, J.A. \& Lehane, B.M. (2006). Effects of width for square centrifuge displacement piles in sand. Proc. International Conf. Physical Modelling in Geotechnics, Hong Kong, 867872.

Stewart, D.P., Boyle, R.S. \& Randolph, M.F. (1998). Experience with a new drum centrifuge. Proc. Centrifuge 98, Tokyo, 35-40.

$\mathrm{Su}, \mathrm{D} . \& \mathrm{Li}, \mathrm{J}$. H. (2013). Three-dimensional finite element study of a single pile response to multidirectional lateral loadings incorporating the simplified state-dependent dilatancy model. Computers and Geotechnics 50, 129-142.

Truong, P. \& Lehane, B.M. (2015). Experimental trends from lateral cyclic tests of piles in sand. Proc. Frontiers in Offshore Geotechnics III, Oslo, 747-752.

Verdure, L., Garnier, J. \& Levacher, D. (2003). Lateral cyclic loading of single piles in sand. International Journal of Physical Modelling in Geotechnics 3, 17-28.

Wichtmann, T., Niemunis, A. \& Triantafyllidis, T. (2010). Strain accumulation in sand due to drained cyclic loading: On the effect of monotonic and cyclic preloading (Miner's rule). Soil Dynamics and Earthquake Engineering 30, No.8, 736-745.

Yang, K. \& Liang, R. (2014). Methods for Deriving p-y Curves from Instrumented Lateral Load Tests. Geotechnical Testing Journal 30, No. 1, 1-8.

Zachert, H., Wichtmann, T. \& Triantafyllidis, T. (2016). Soil Structure Interaction of Foundations for Offshore Wind Turbines. Proc. 26th International Ocean and Polar Engineering Conf., Rhodes, 68-75.

Zania V., and Hededal O. (2011). Effect of soil - pile interface behaviour on laterally loaded piles. Proc. $13^{\text {th }}$ International Conf. Civil, Structural and Environmental Engineering Computing, B.H.V. Topping and Y. Tsompanakis, (Editors), Civil-Comp Press, Chania, Greece, 84.

Zania, V. (2014). Natural vibration frequency and damping of slender structures founded on monopiles. Soil dynamics and Earthquake engineering 59, 8-20. 


\section{Accepted manuscript doi: 10.1680/jgeot.17.p.203}

Table 1. Cyclic pile test program

\begin{tabular}{|c|c|c|c|c|c|c|c|c|c|c|}
\hline \multirow[t]{3}{*}{ Test no. } & \multirow[t]{3}{*}{ Centrifuge } & \multirow{3}{*}{$\begin{array}{l}\text { g } \\
\text { level }\end{array}$} & \multirow{3}{*}{$\begin{array}{l}D_{\mathbf{r}} \\
(\%)\end{array}$} & \multirow{3}{*}{$\begin{array}{l}\text { Total } \\
\text { no. of } \\
\text { Cycles }\end{array}$} & \multicolumn{6}{|c|}{ Cyclic load characteristics } \\
\hline & & & & & \multicolumn{2}{|c|}{ Load 1} & \multicolumn{2}{|c|}{ Load 2} & \multicolumn{2}{|c|}{ Load 3} \\
\hline & & & & & $\zeta_{c}$ & $\zeta_{\mathbf{b}}$ & $\zeta_{c}$ & $\zeta_{\mathbf{b}}$ & $\zeta_{c}$ & $\zeta_{\mathrm{b}}$ \\
\hline UWA-M & Drum & 250 & 68 & Mono & - & - & - & - & - & - \\
\hline UWA-C-1 & Drum & 250 & 68 & 50 & 0.01 & 1.04 & - & - & - & - \\
\hline UWA-C-2 & Drum & 250 & 68 & 50 & 0.33 & 1.05 & - & - & - & - \\
\hline UWA-C-3 & Drum & 250 & 68 & 50 & 0.71 & 1.05 & - & - & - & - \\
\hline UWA-C-4 & Drum & 250 & 68 & 50 & 0.04 & 0.48 & - & - & - & - \\
\hline UWA-C-5 & Drum & 250 & 68 & 50 & 0.33 & 0.48 & - & - & - & - \\
\hline UWA-C-6 & Drum & 250 & 68 & 50 & 0.72 & 0.48 & - & - & - & - \\
\hline DTU-M-1 & Beam & 60 & 60 & Mono & - & - & - & - & - & - \\
\hline DTU-C-1 & Beam & 60 & 64 & 1500 & 0.05 & 0.49 & 0.04 & 0.74 & 0.05 & 1.00 \\
\hline DTU-C-2 & Beam & 60 & 58 & 1500 & 0.03 & 1.00 & 0.12 & 0.49 & 0.06 & 0.72 \\
\hline DTU-C-3 & Beam & 60 & 51 & 1500 & 0.01 & 0.74 & 0.02 & 0.49 & 0.03 & 1.00 \\
\hline \multirow[t]{2}{*}{ DTU-C-4 } & Beam & 60 & 52 & 900 & 0.50 & 0.50 & - & 0.50 & - & 0.50 \\
\hline & & & & & & & 0.50 & & 1.00 & \\
\hline \multirow[t]{2}{*}{ DTU-C-5 } & Beam & 60 & 63 & 900 & - & 0.47 & - & 0.45 & 0.47 & 0.43 \\
\hline & & & & & 0.53 & & 1.15 & & & \\
\hline \multirow[t]{2}{*}{ DTU-C-6 } & Beam & 60 & 50 & 900 & - & 0.45 & 0.46 & 0.45 & - & 0.43 \\
\hline & & & & & 1.13 & & & & 0.55 & \\
\hline DTU-M-2 & Beam & 60 & 88 & Mono & - & - & - & - & - & - \\
\hline DTU-C-7 & Beam & 60 & 85 & 1500 & 0.01 & 0.53 & 0.02 & 0.80 & 0.02 & 1.10 \\
\hline \multirow[t]{2}{*}{ DTU-C-8 } & Beam & 60 & 95 & 900 & 0.53 & 0.55 & - & 0.58 & - & 0.59 \\
\hline & & & & & & & 0.42 & & 0.82 & \\
\hline
\end{tabular}




\section{Accepted manuscript doi: 10.1680/jgeot.17.p.203}

Table 2. Summary of test pile properties from this study and tests for comparison study

\begin{tabular}{|c|c|c|c|c|c|}
\hline & $\begin{array}{l}\text { UWA } \\
\text { drum } \\
\text { centrifuge }\end{array}$ & $\begin{array}{l}\text { DTU beam } \\
\text { centrifuge }\end{array}$ & $\begin{array}{l}\text { Klinkvort \& } \\
\text { Hededal } \\
\text { (2013) }\end{array}$ & $\begin{array}{l}\text { Rosquoet } e t \\
\text { al. (2007) }\end{array}$ & $\begin{array}{l}\text { Li et al. } \\
(2015) \\
\text { Field tests }\end{array}$ \\
\hline $\mathrm{D}_{\text {model }}(\mathrm{m})$ & $0.011^{(1)}$ & $0.040^{(1)}$ & $\begin{array}{l}0.028^{(1)} \text { and } \\
0.040^{(1)}\end{array}$ & 0.018 & \\
\hline $\mathrm{D}_{\text {prototype }}(\mathrm{m})$ & 2.75 & 3.92 & 3.0 & 0.72 & 0.34 \\
\hline $\mathrm{t}_{\mathrm{metal}}(\mathrm{m})$ & 0.001 & 0.0015 & Solid & 0.0015 & 0.014 \\
\hline$t_{\text {epoxy }}(m)$ & 0.0005 & 0.001 & 0.002 & & \\
\hline $\mathrm{D} / \mathrm{t}$ & 7.3 & 16 & $\mathrm{n} / \mathrm{a}$ & 12 & 24 \\
\hline $\begin{array}{l}\text { EI }_{\text {prototype }} \\
\left(\mathrm{GNm}^{2}\right)\end{array}$ & 88.1 & 74.4 & $77.7^{(2)}$ to $522^{(2)}$ & 0.476 & $0.038^{(2)}$ \\
\hline Sand type & $\begin{array}{l}\text { Fine Silica } \\
\text { Sand }\end{array}$ & $\begin{array}{l}\text { Fontainebleau } \\
\text { Silica Sand }\end{array}$ & $\begin{array}{l}\text { Fontainebleau } \\
\text { Silica Sand }\end{array}$ & $\begin{array}{l}\text { Fontainebleau } \\
\text { Silica Sand }\end{array}$ & $\begin{array}{l}\text { Blessington } \\
\text { fine sand }\end{array}$ \\
\hline $\mathrm{D}_{\mathrm{r}} \%$ & 68 & 50 to 99 & 79 to 96 & 86 & $100 \%$ \\
\hline $\mathrm{L} / \mathrm{D}$ & 11.4 & 6 & 6 & 16.7 & 6.5 \\
\hline$e / D$ & 2 & 3 & 15 & 2.22 & 1.17 \\
\hline Toe condition & Open & Open & Closed & Open & Open \\
\hline Installation & $\begin{array}{l}\text { Jacked at } \\
1 \mathrm{~g}\end{array}$ & Jacked at $60 \mathrm{~g}$ & $\begin{array}{l}\text { Jacked in } \\
\text { lower g field }\end{array}$ & Driven at $1 \mathrm{~g}$ & Driven \\
\hline
\end{tabular}

(1) Includes thickness of epoxy.

${ }^{(2)}$ Assuming Young's modulus of elasticity of $200 \mathrm{GPa}$. 


\section{Accepted manuscript doi: 10.1680/jgeot.17.p.203}

Table 3. Cyclic triaxial test

\begin{tabular}{lllllllll}
\hline & TX-1 & TXC-1 & TX-2 & TXC-2 & \multicolumn{3}{c}{ TXC-3 } \\
\cline { 6 - 8 } & & & & & Load 1 & Load 2 & Load 3 \\
\hline Type & Mono & Cyclic & Mono & Cyclic & Cyclic & Cyclic & Cyclic \\
$\mathrm{D}_{\mathrm{r}}(\%)$ & 90 & 90 & 55 & 55 & 55 & 55 & 55 \\
$\mathrm{q}_{\mathrm{f}}(\mathrm{kPa})$ & 421 & 411 & 319 & 342 & - & - & 337 \\
$\mathrm{q}_{\max }(\mathrm{kPa})$ & - & 207 & - & 242 & 170 & 235 & 66 \\
$\mathrm{~N}$ & - & 1000 & - & 1000 & 500 & 500 & 500 \\
$\alpha_{\text {triax }}$ & - & 0.09 & - & 0.14 & 0.13 & - & - \\
\hline
\end{tabular}




\section{Accepted manuscript doi: 10.1680/jgeot.17.p.203}

Figure 1. Schematic diagram for cycle number assignment and determining rotational stiffness

Figure 2. Schematic plan view of UWA drum centrifuge pile test setup

Figure 3. Schematic elevation of DTU beam centrifuge pile test setup

Figure 4. Monotonic lateral pile test results

Figure 5. (a) Pile rotations at sand surface for one-way cyclic tests, and (b) Normalised pile rotations for $\zeta_{\mathrm{c}} \approx 0$

Figure 6. Average relative increase in reload stiffness from $\mathrm{K}_{\mathrm{r} 1}$ in DTU tests

Figure 7. Typical profiles of bending moment, net pressure and pile deflection (a) Test DTU-C-1 $\left(\zeta_{\mathrm{c}}=0.05, \zeta_{\mathrm{b}}=0.49, \mathrm{D}_{\mathrm{r}}=64 \%\right)(\mathrm{b})$ Test DTU-C-2 $\left(\zeta_{\mathrm{c}}=0.03, \zeta_{\mathrm{b}}=1.00, \mathrm{D}_{\mathrm{r}}=58 \%\right)(\mathrm{c})$ Test DTU-C-6 $\left(\zeta_{\mathrm{c}}=-\right.$ $\left.1.13, \zeta_{\mathrm{b}}=0.45, \mathrm{D}_{\mathrm{r}}=50 \%\right)(\mathrm{d})$ Test DTU-C-7 $\left(\zeta_{\mathrm{c}}=0.01, \zeta_{\mathrm{b}}=0.53, \mathrm{D}_{\mathrm{r}}=85 \%, \mathrm{~L} / \mathrm{D}=6\right)(\mathrm{e})$ Test UWA-C-4 $\left(\zeta_{\mathrm{c}}=\right.$ $\left.0.04, \zeta_{\mathrm{b}}=0.48, \mathrm{D}_{\mathrm{r}}=68 \%, \mathrm{~L} / \mathrm{D}=11.4\right)$

Figure 8. Pile rotation at peak load under various cycles in (a) cyclic load sequences with (a) $\zeta_{\mathrm{c}} \approx 0$ and $(\mathrm{b}) \zeta_{\mathrm{b}} \approx 0.5$

Figure 9. Post-cyclic response in (a) UWA tests $(\mathrm{Dr}=68 \%)$ and (b) DTU tests with $\mathrm{D}_{\mathrm{r}}$ given in parentheses

Figure 10. Relationship of (a) $\alpha_{\mathrm{y}}$ with $\mathrm{D}_{\mathrm{r}}$ for $\zeta_{\mathrm{c}} \sim 0$ and (b) $\alpha_{\mathrm{y}}$ normalised for effects of $\mathrm{D}_{\mathrm{r}}$ for varying $\zeta_{\mathrm{c}}$ ratios

Figure 11. Triaxial tests in Fontainebleau sand (a) comparison of monotonic and cyclic tests and (b) variation of axial strain with number of cycles.

Figure 12. Variations of measured and calculated rotation accumulation for DTU tests 


\section{Accepted manuscript doi: 10.1680/jgeot.17.p.203}

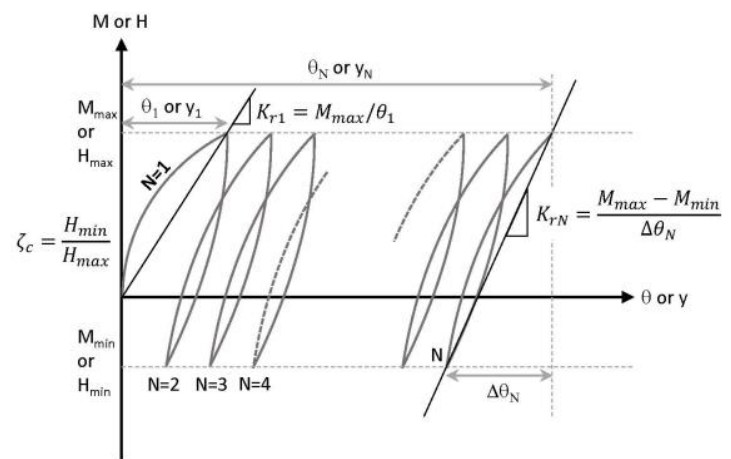

Figure 1. Schematic diagram for cycle number assignment and determining rotational stiffness 


\section{Accepted manuscript doi: 10.1680/jgeot.17.p.203}

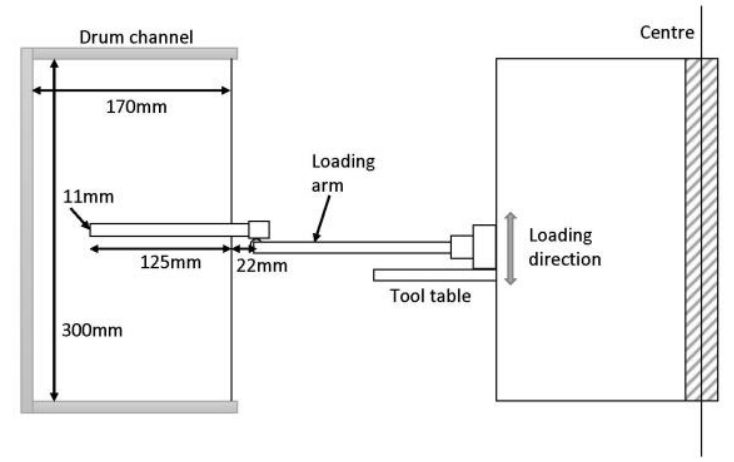

Figure 2. Schematic plan view of UWA drum centrifuge pile test setup 


\section{Accepted manuscript doi: 10.1680/jgeot.17.p.203}

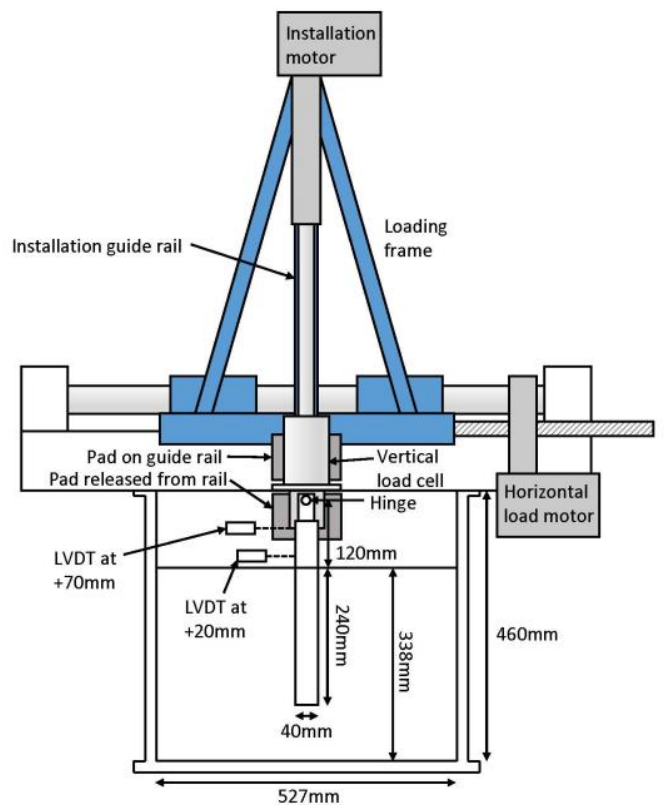

Figure 3. Schematic elevation of DTU beam centrifuge pile test setup 


\section{Accepted manuscript doi: 10.1680/jgeot.17.p.203}
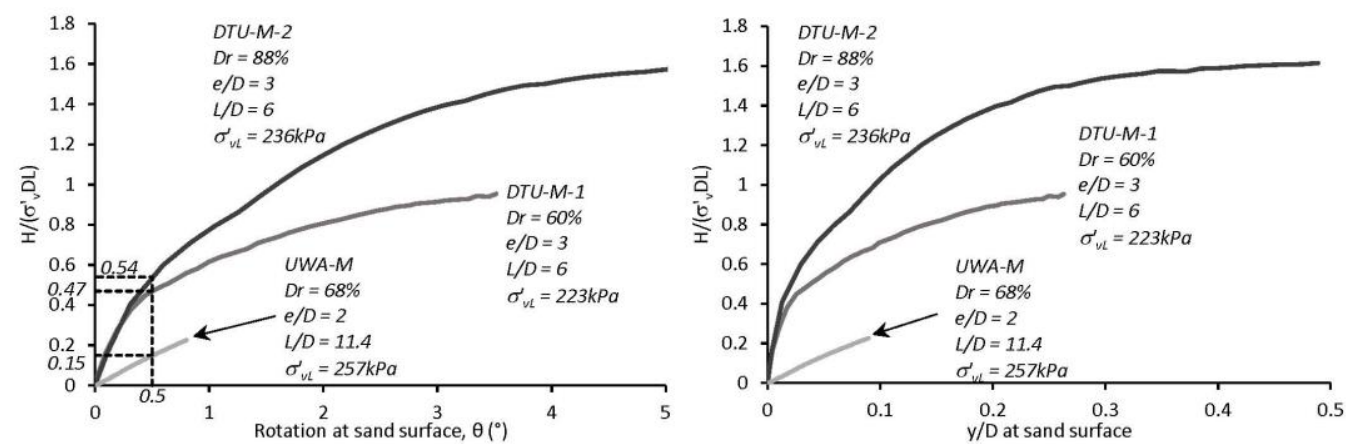

Figure 4. Monotonic lateral pile test results 


\section{Accepted manuscript doi: 10.1680/jgeot.17.p.203}

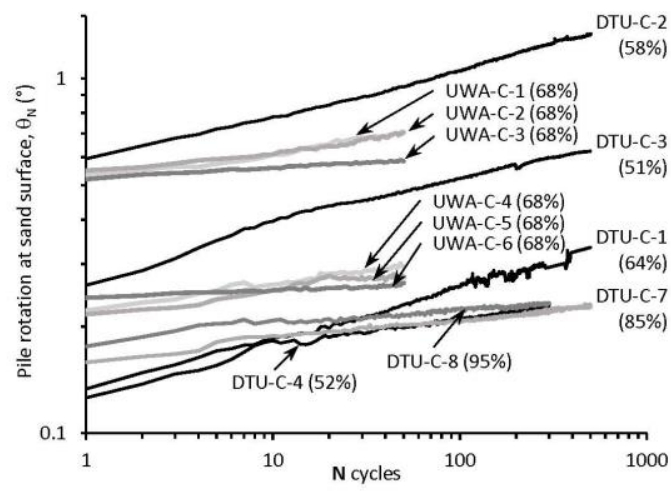

(a)

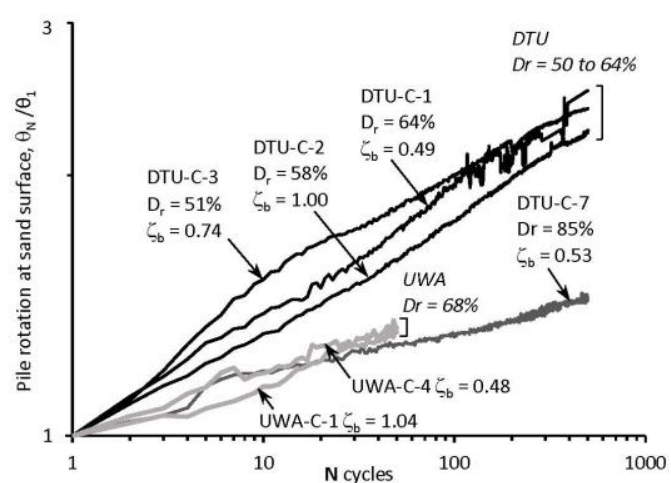

(b)

Figure 5. (a) Pile rotations at sand surface for one-way cyclic tests, and (b) Normalised pile rotations for $\zeta_{c} H O$ 


\section{Accepted manuscript doi: 10.1680/jgeot.17.p.203}

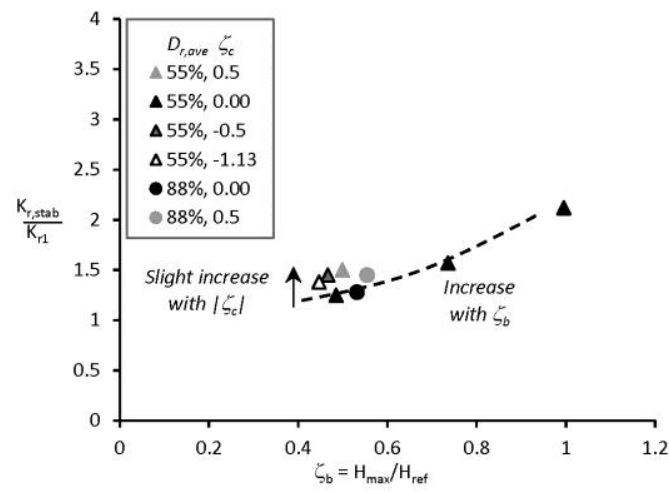

Figure 6. Average relative increase in reload stiffness from $K_{r l}$ in DTU tests 


\section{Accepted manuscript doi: 10.1680/jgeot.17.p.203}
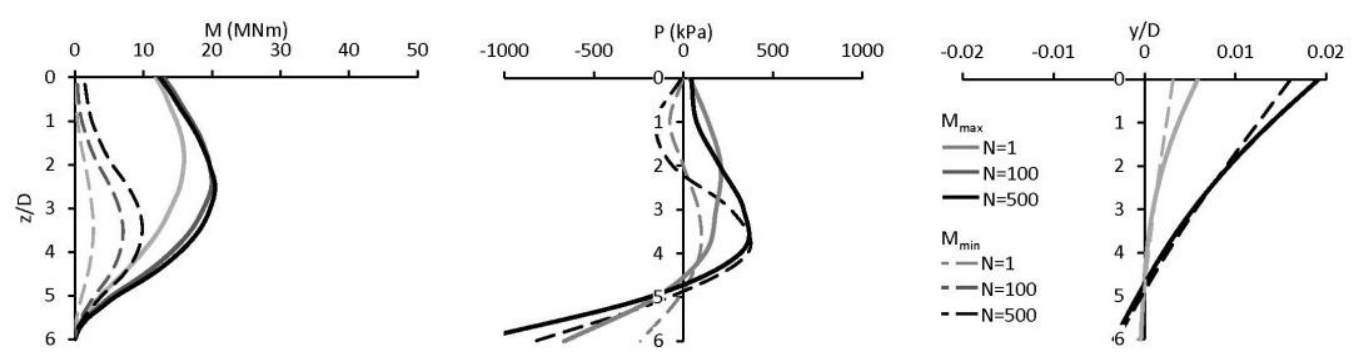

(a) Test DTU-C-1 $\left(\zeta_{\mathrm{c}}=0.05, \zeta_{\mathrm{b}}=0.49, \mathrm{D}_{\mathrm{r}}=64 \%\right)$
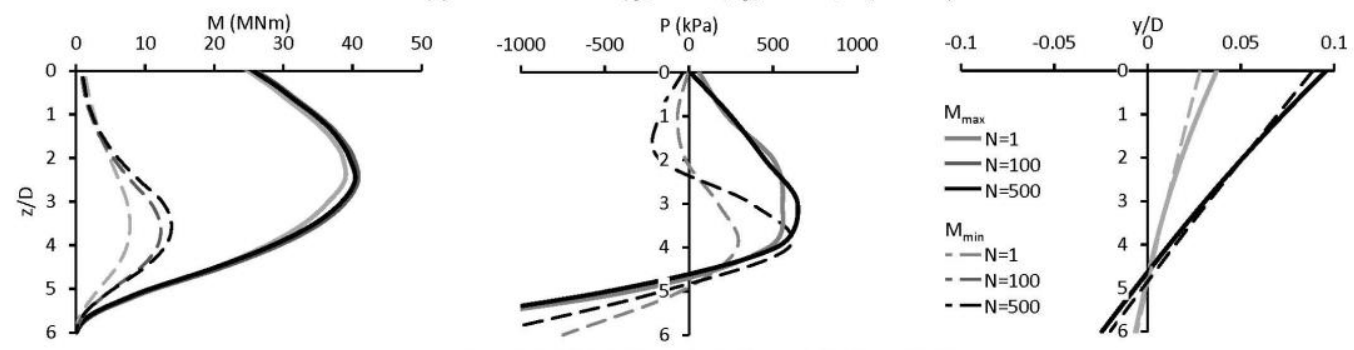

(b) Test DTU-C-2 $\left(\zeta_{\mathrm{c}}=0.03, \zeta_{\mathrm{b}}=1.00, \mathrm{D}_{\mathrm{r}}=58 \%\right)$
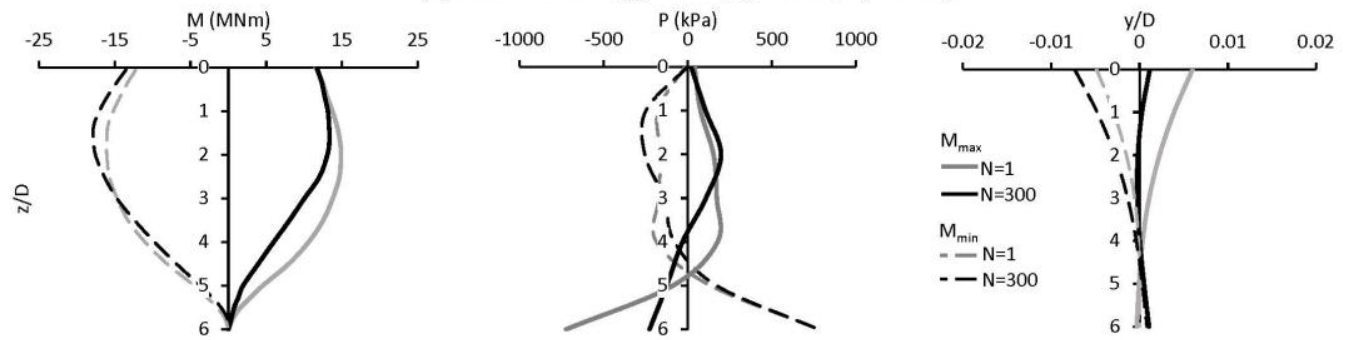

(c) Test DTU-C-6 $\left(\zeta_{\mathrm{c}}=-1.13, \zeta_{\mathrm{b}}=0.45, \mathrm{D}_{\mathrm{r}}=50 \%\right)$
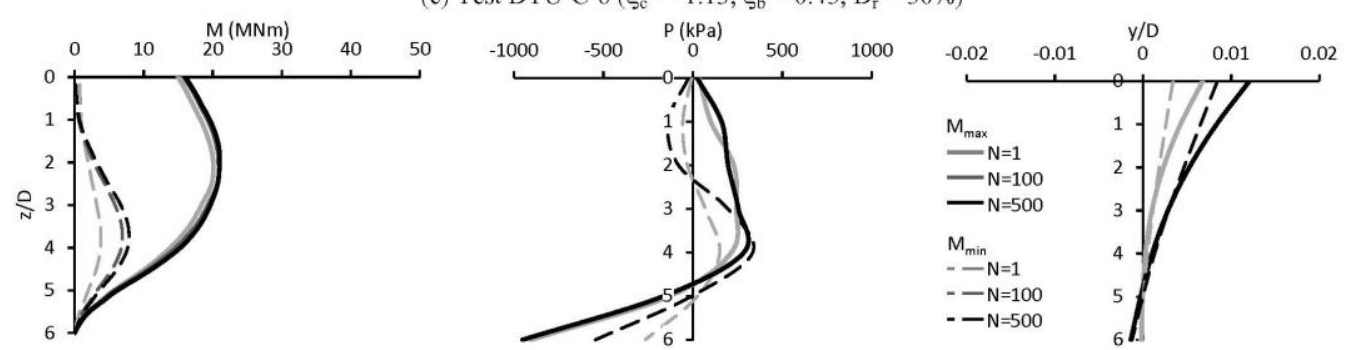

(d) Test DTU-C-7 $\left(\zeta_{\mathrm{c}}=0.01, \zeta_{\mathrm{b}}=0.53, \mathrm{D}_{\mathrm{r}}=85 \%, \mathrm{~L} / \mathrm{D}=6\right)$
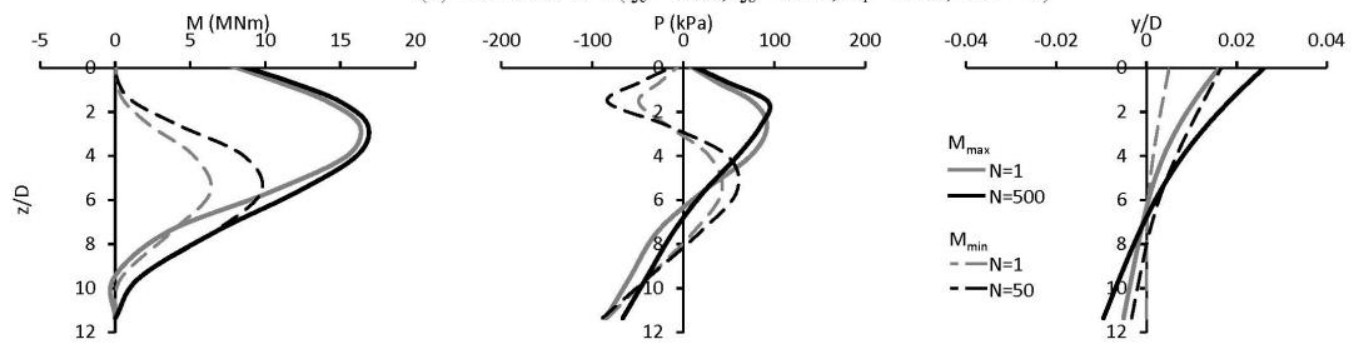

(e) Test UWA-C-4 $\left(\zeta_{\mathrm{c}}=0.04, \zeta_{\mathrm{b}}=0.48, \mathrm{D}_{\mathrm{r}}=68 \%, \mathrm{~L} / \mathrm{D}=11.4\right)$

Figure 7. Typical profiles of bending moment, net pressure and pile deflection 


\section{Accepted manuscript doi: 10.1680/jgeot.17.p.203}

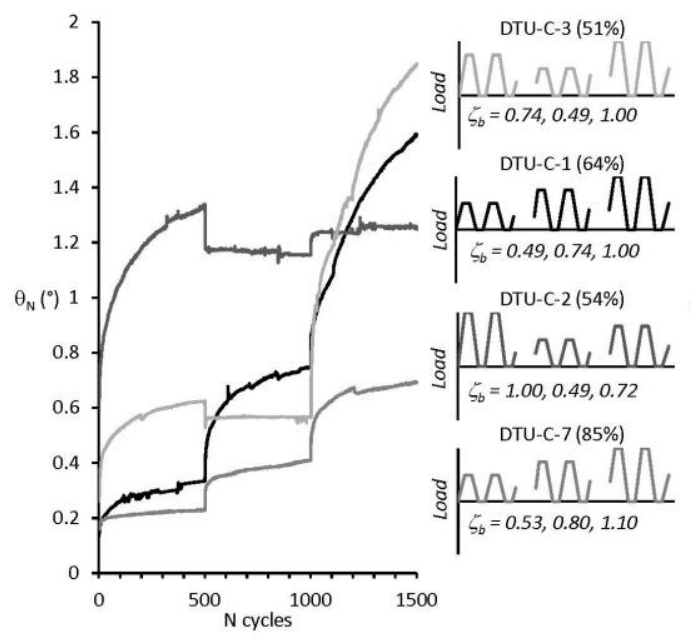

(a)

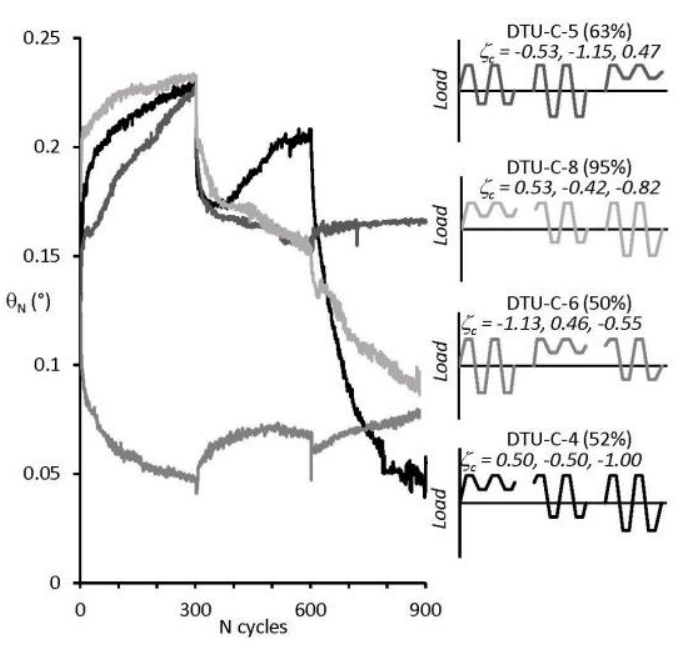

(b)

Figure 8. Pile rotation at peak load under various cycles in (a) cyclic load sequences with (a) $\zeta_{\mathrm{c}} H O$ and (b) $\zeta_{\mathrm{b}} H O .5$ 


\section{Accepted manuscript doi: 10.1680/jgeot.17.p.203}

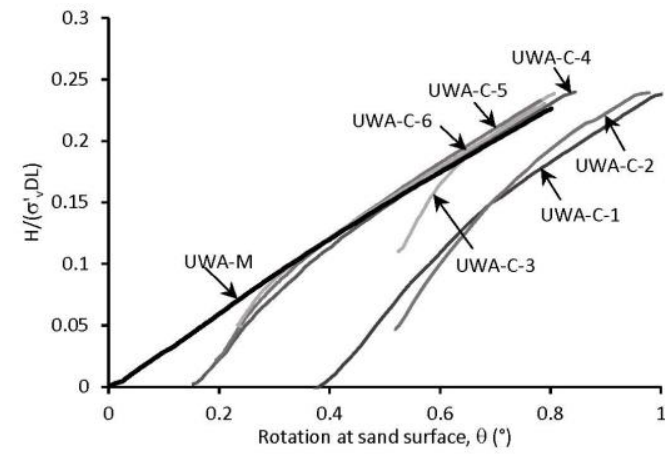

(a)

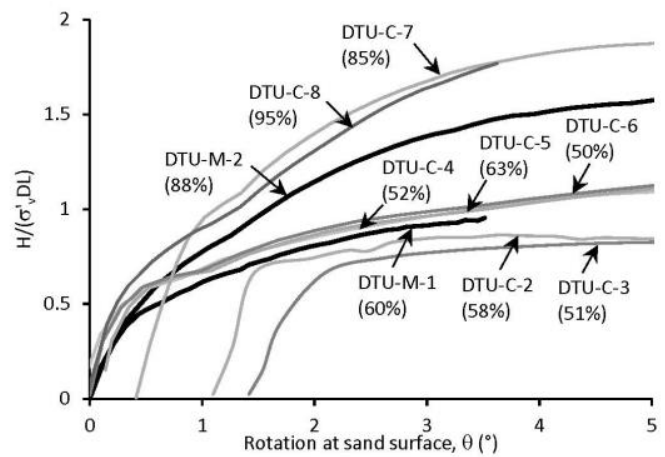

(b)

Figure 9. Post-cyclic response in (a) UWA tests $\left(\mathrm{Dr}=68 \%\right.$ ) and (b) DTU tests with $D_{r}$ given in parentheses 


\section{Accepted manuscript doi: 10.1680/jgeot.17.p.203}

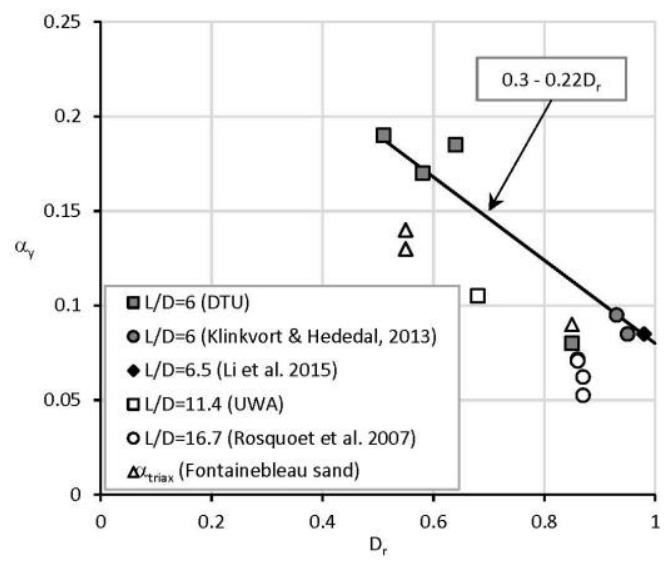

(a)

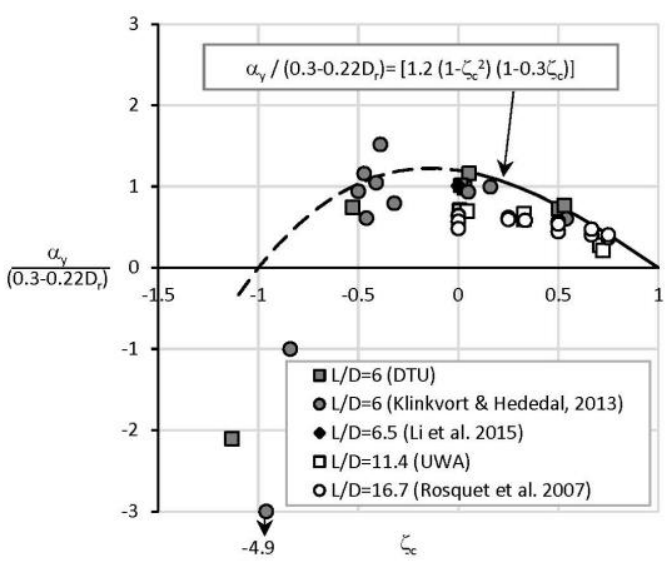

(b)

Figure 10. Relationship of (a) $\alpha_{y}$ with $D_{r}$ for $\zeta_{c} \sim 0$ and (b) $\alpha_{y}$ normalised for effects of Dr for varying zc ratios 


\section{Accepted manuscript doi: 10.1680/jgeot.17.p.203}

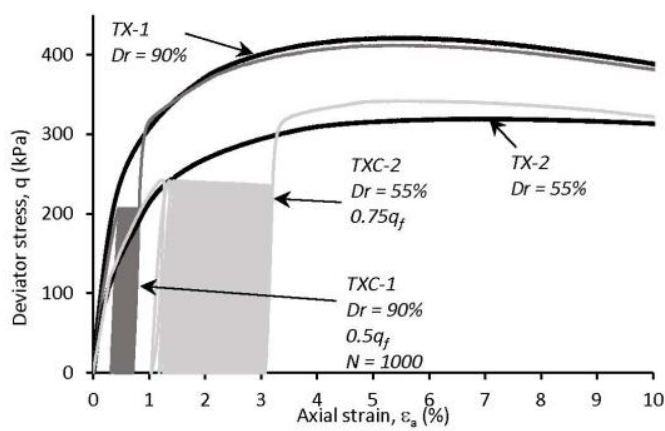

(a)

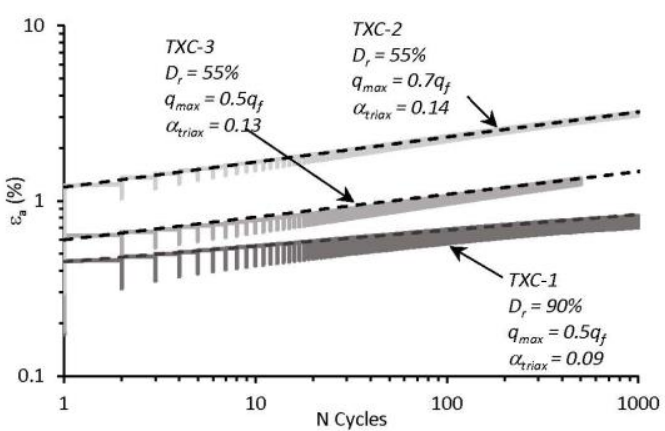

(b)

Figure 11. Triaxial tests in Fontainebleau sand (a) comparison of monotonic and cyclic tests and (b) variation of axial strain with number of cycles. 


\section{Accepted manuscript doi: 10.1680/jgeot.17.p.203}

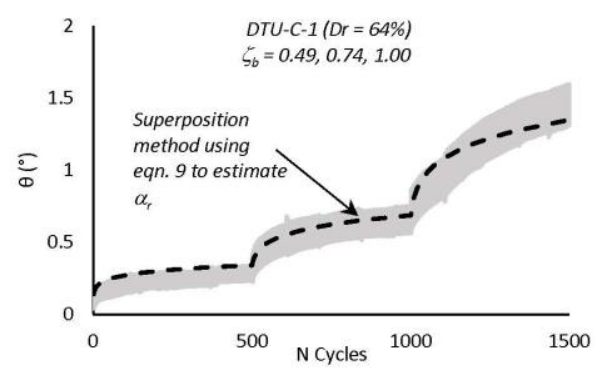

(a)

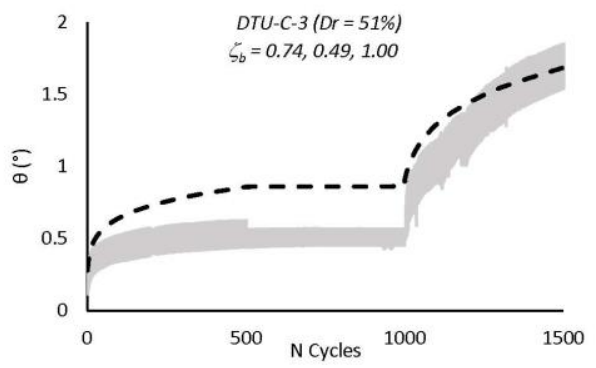

(c)

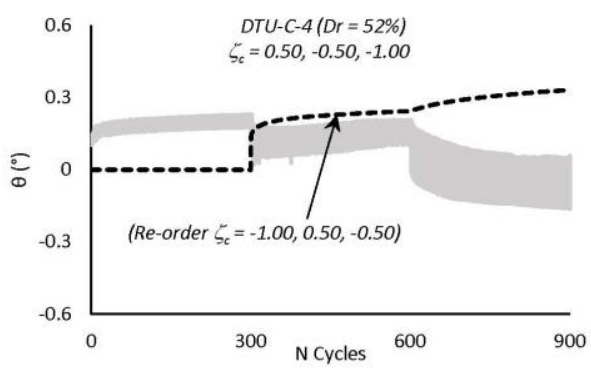

(e)

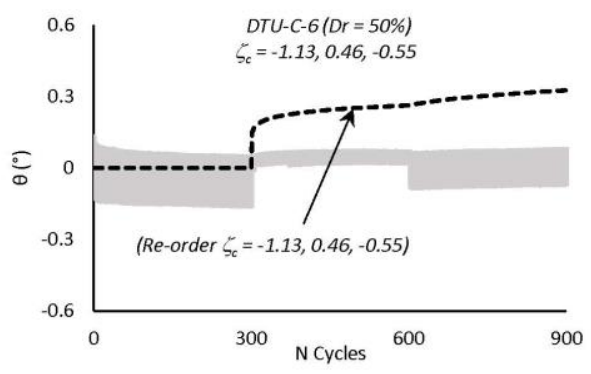

(g)

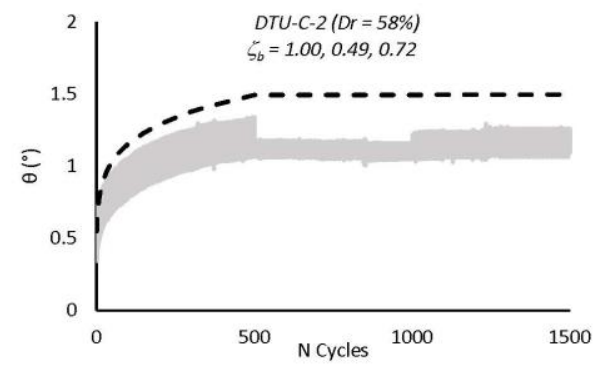

(b)

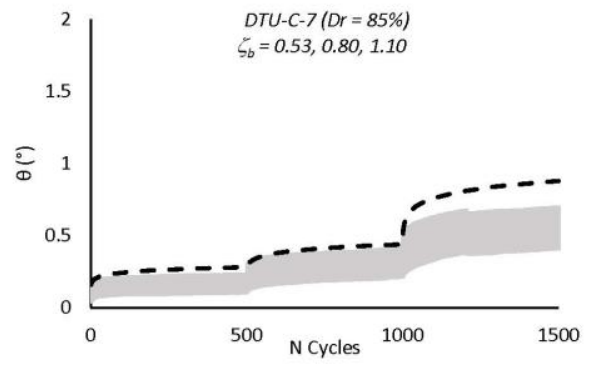

(d)

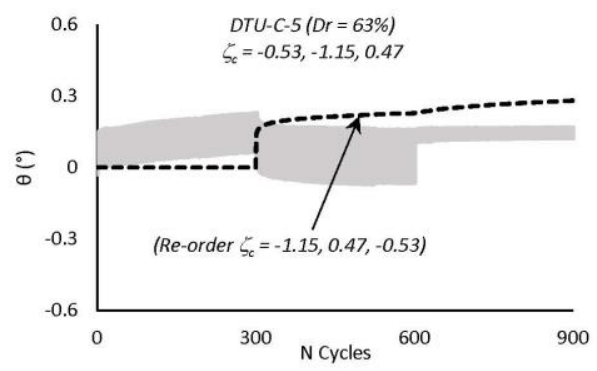

(f)

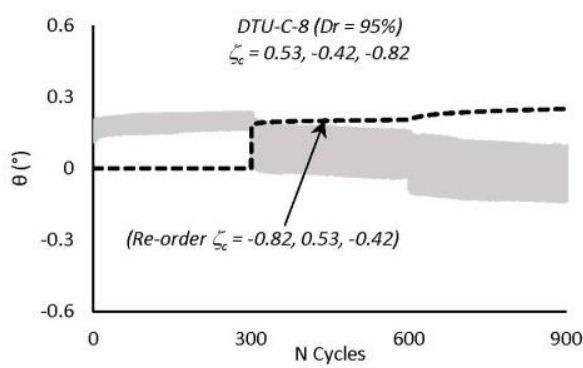

(h)

Figure 12. Variations of measured and calculated rotation accumulation for DTU tests 